\title{
CALLITRIS GLAUCOPHYLLA, AUSTRALIA'S 'WHITE CYPRESS PINE' - A NEW NAME FOR AN OLD SPECIES
}

JoY THOMPSON \& L. A. S. JoHNSON

(Accepted for publication 19.12.1984)

\begin{abstract}
Thompson, Joy \& Johnson, L. A. S. (National Herbarium of New South Wales, Royal Botanic Gardens, Sydney, Australia 2000) 1986. Callitris glaucophylla, Australia's 'White Cypress Pine' - a new name for an old species. Telopea 2(6): 731-736 - The widespread conifer of temperate Australia, 'White Cypress Pine', is distinguished from related species and named Callitris glaucophylla.
\end{abstract}

The species widely known as 'White Cypress Pine' appears to lack a 'correct' botanical name. All the names it has carried through its extensive literature are either not legitimate under the International Code of Botanical Nomenclature, or are legally the property of other species. The correct disposition, under the Code, of Callitris hugelii (Carrière) Franco (1952) was questioned by Blake (1959) and remains in doubt. Relevant literature has been covered in the publications of Garden (1957), Blake (1959) and Thompson (1961).

Carrière's concept contains more than one element. In spite of the obvious Western Australian content indicated by the protologue and the name ' $F$. de Hügel', Franco suggested that a specimen, Moreton Bay, N(ew) H(olland), Leichhardt, 1854 ( $\mathrm{P}$, photo NSW), was part of Carrière's original concept. As Blake indicated, it is quite probably not so, and the chief element in that concept was certainly a plant (or plants) cultivated in Paris of which there is no herbarium specimen. The rather fragmentary Leichhardt specimen was seen by Blake who identified it as the coastal C. columellaris s. str. Although in 1854 (given as the date of collection in a hand other than Leichhardt's) Leichhardt was in inland Queensland well away from the habitat of that species, Blake mentioned several features that are generally diagnostic of $C$. columellaris s. str. Uncertainty as to the relevance of this specimen to the protologue regardless of its identity renders it an unsuitable lectotype. We therefore regard the name Frenela hugelii as a name of uncertain application.

Both of us have observed for many years the three taxa that were united by Blake under $C$. columellaris, and we continue to hold the opinion expressed by Thompson (1961), that they are distinct species. As we feel sure that others share this opinion and treat the taxon in the broad sense only because there is no name that they can apply with confidence to the most widespread and economically important component, we are naming it here as a new species.

Callitris glaucophylla Thompson \& Johnson, sp. nov.

Arbor vel frutex magnus cortice non nigrescente modice rugoso sed fissuris non profundis, ramis plerumque patentibus, ramulis assimilatoribus plerumque glaucis nunquam densissimus atrovirentibusque, foliis $1-3 \mathrm{~mm}$ longis dorsaliter rotundatis, strobilis solitariis non persistentibus, squamis tenuis paene ad basin separantibus. 


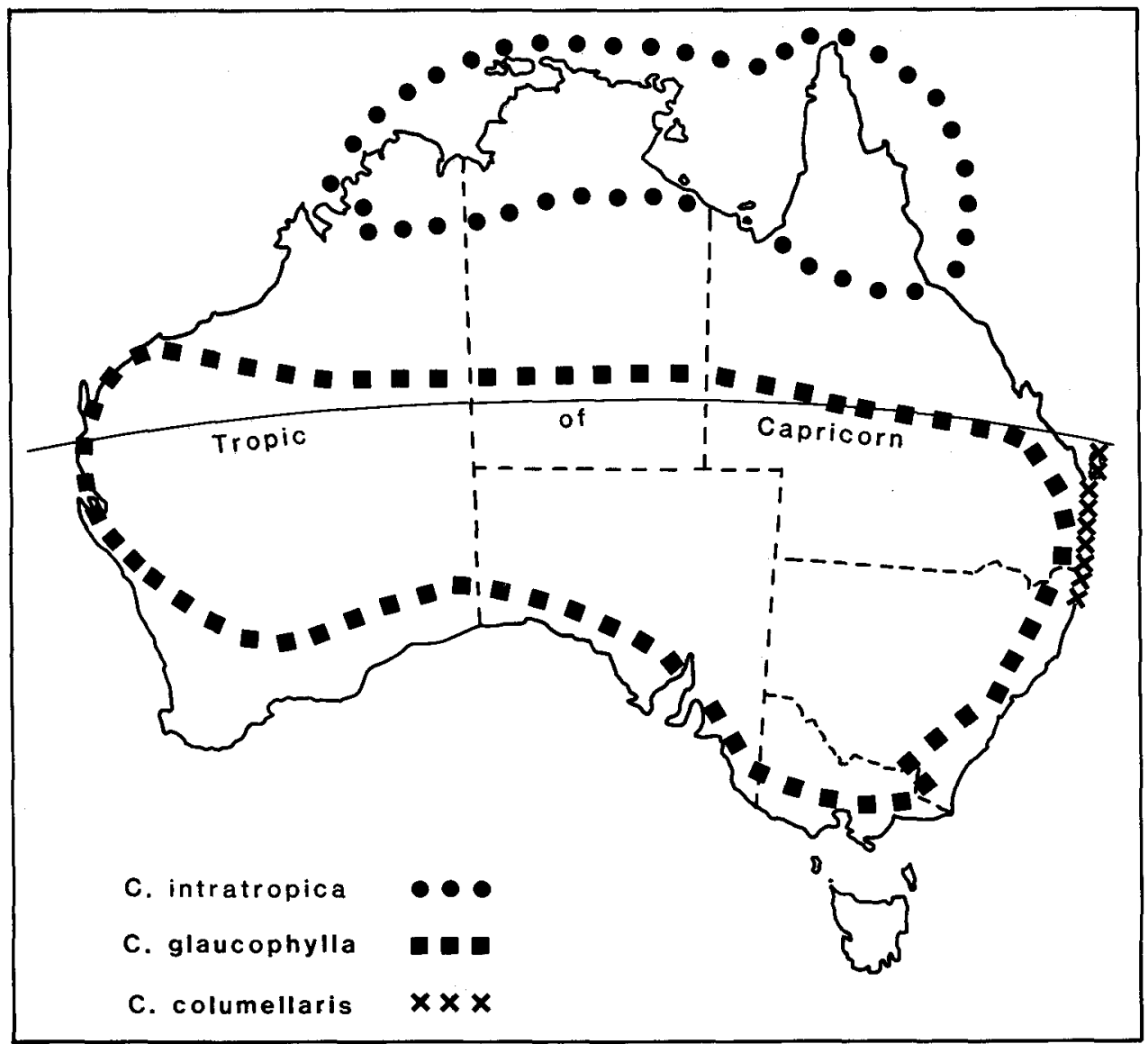

Map. Generalized distributions of Callitris intratropica, C. glaucophylla and C. columellaris.

A tree or shrub with rough, but not dark and deeply fissured, bark, the branches usually but not invariably spreading, the foliage usually glaucous and never dense and dark green, the leaves 1-3 $\mathrm{mm}$ long with the dorsal surface rounded, the cones solitary and not long-persistent, their valves thin and separating almost to the base.

Holotypus: 'Noonah Vale', c. $23 \mathrm{~km}$ SW. of Garah, New South Wales, $2^{\circ} 08^{\prime} \mathrm{S} 140^{\circ} 26^{\prime} \mathrm{E}$, K. L. Wilson 1942, 5.10.1978 (NSW; Isotypi: BRI, K, L, RSA).

In Western Australia and the Northern Territory, $C$. intratropica R. T. Baker \& H. G. Smith (1910) is well separated from $C$. glaucophylla geographically, being well within the tropics many degrees northward of the southern species (see map). In Queensland it may not have achieved such complete separation but the collections of both BRI and NSW show no record of Callitris between $20^{\circ} \mathrm{S}$ latitude and the Tropic of Capricorn. It is probable that characters not preserved in herbarium material could be used in a study of populations in inland northern Queensland. Stocker (1966) found marked differences of foliage and form between three-year-old trees of $C$. intratropica and those of $C$. glaucophylla, while chemical analysis, as summarized by Rudman (1964), has shown the wood of $C$. intratropica to be low in l-citronellic acid and high in guaiol, while that of $C$. glaucophylla is high in l-citronellic acid and low in 
guaiol. Rudman (1963) considered the control of these substances' occurrence to be genetic.

C. columellaris F. Muell (in the strict sense, not as expanded by Blake 1959) and $C$. glaucophylla occupy different habitats and are very different in the appearance of their foliage, habit and bark. These differences are retained in the numerous cultivated specimens. $C$. columellaris, with its fine, dense and usually very dark green foliage, has a strikingly different appearance from C. glaucophylla, even when cultivated under conditions very much removed from the deep coastal sands of its warm-temperate native habitat.

The distinction between $C$. glaucophylla and its two close relatives is difficult to define from herbarium material although this does not preclude the recognition of the three taxa as species.

The relevant section of the key in Garden (1957) still serves to distinguish most specimens.

\section{KEY TO THE SPECIES}

1. Dorsal surface of the leaf rounded.

2. Cones solitary on slender fruiting branchlets, the cone-scales separating almost to the base in the mature cone.

3. A tropical species; cones usually $1.8 \mathrm{~cm}$ or less in diameter C. intratropica 1 .

*3. Not tropical species; cones often more than $1.8 \mathrm{~cm}$ in diameter.

4. An inland species; foliage usually glaucous C. glaucophylla 3 .

*4. A coastal species; foliage usually green C. columellaris 2 .

*2. Cones solitary or several together on stout fruiting branchlets, the cone-scales failing to separate near the base in the mature cone.

The range and means of five cone characters easily measured from herbarium specimens are presented here in the form of polygraphs (Figs 1-3). These are based on 40 specimens of $C$. glaucophylla, 17 of $C$. intratropica and 14 of $C$. columellaris selected from the herbarium in 1970. A sampling of material collected since that date shows no significant departure from these findings. Ranges of almost all characters show overlap but the combinations are different for each taxon, as shown by the different shapes of the polygraph. Inspection of these demonstrates that no one taxon is intermediate overall between the other two.

Given an adequate specimen, with data on habit, one can assign it to one of the three taxa without pre-knowledge of provenance. Since there is no population overlap or intergradation it is appropriate to recognize the three taxa as species rather than subspecies.

All these species are likely to be completely interfertile, but fertility barriers do not coincide with practical specific limits in the group to which these Cypress Pines belong. The less closely related but distinctive and partly sympatric $C$. preissii hybridizes with C. glaucophylla with no diminution of pollen fertility or seed viability in the progeny (D. Christophel \& A. Pillman pers. comm. 1976). Indeed, considerable hybrid populations of $C$. glaucophylla with various subspecies of C. preissii occur in such places as the Flinders Ranges of South Australia, the Murray River and mallee regions of South Australia, Victoria and New South Wales, and as 'phantoms' in northern New South Wales and southern Queensland (Thompson 1961; Johnson pers. obs.). 

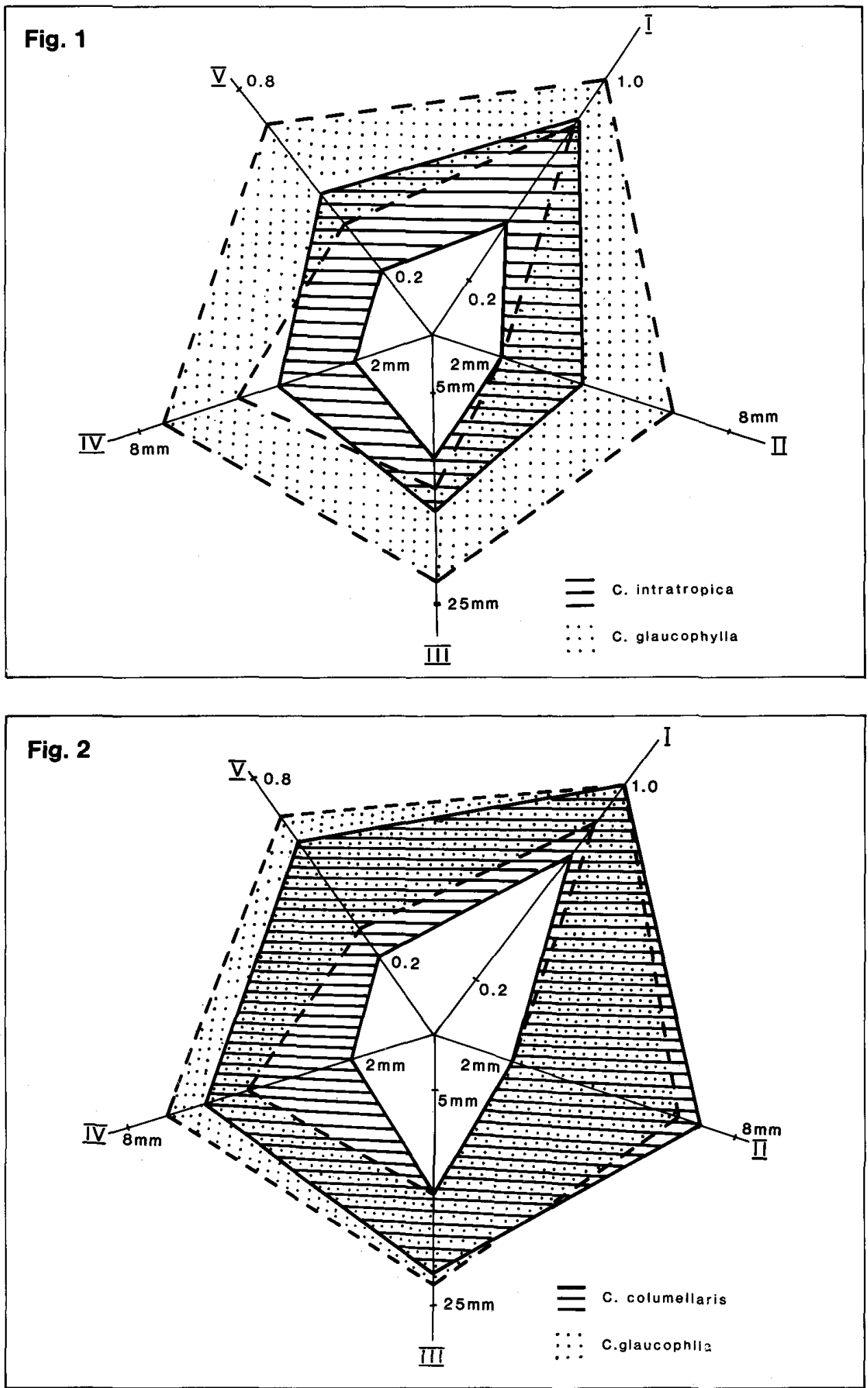


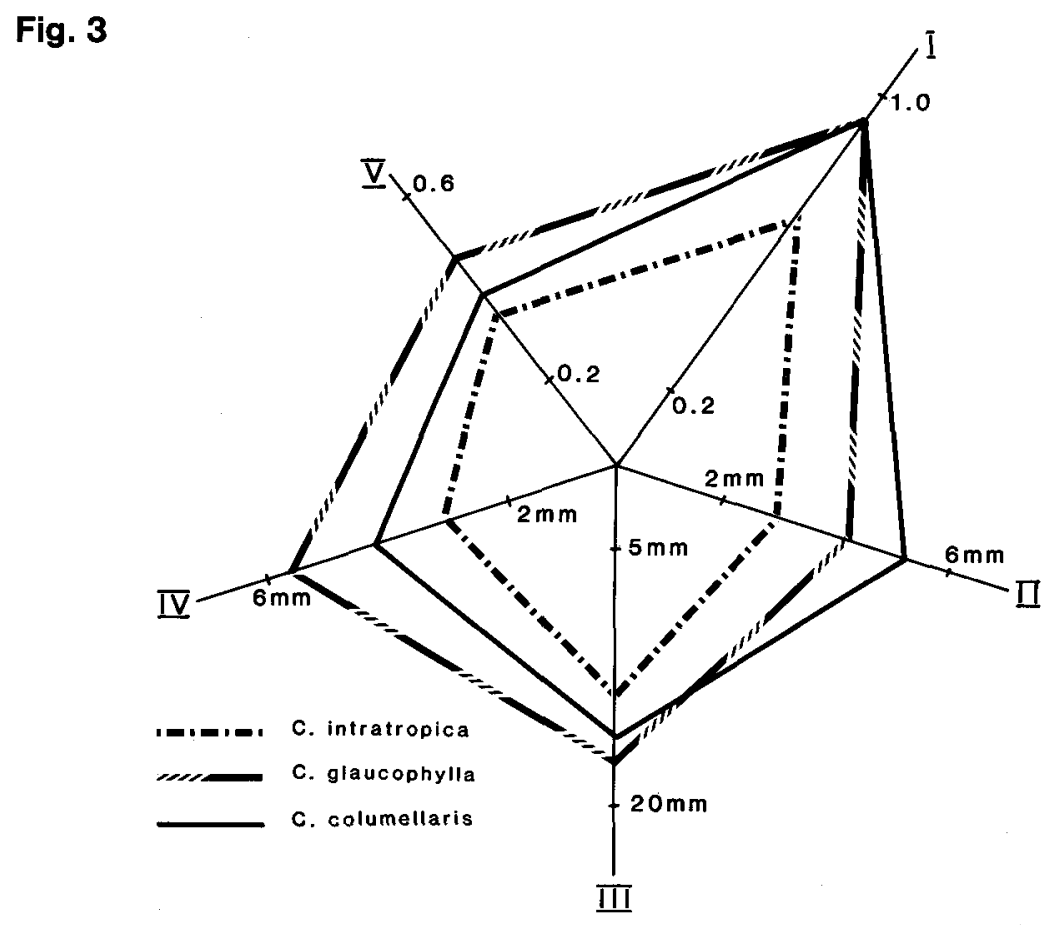

Fig. 1. C. intratropica-C. glaucophylla polygraph showing the range of variation of selected characters. I breadth (at the middle): breadth (maximum) ratio of the small cone-scale; II columella length; III cone length; IV breadth (at the middle) of the cone-scale; V breadth (at the middle): length ratio of the small cone-scale.

Fig. 2. C. columellaris-C. glaucophylla polygraph showing range of variation of selected characters. I breadth (at the middle): breadth (maximum) ratio of the small cone-scale; II columella length; III cone length; IV breadth (at the middle) of the small cone-scale; $V$ breadth (at the middle): length ratio of the small cone-scale.

Fig. 3. C. intratropica-C. columellaris-C. glaucophylla polygraph showing the means of values for selected characters. I breadth (at the middle): breadth (maximum) ratio of the small cone-scale; II columella length; III cone length; IV breadth (at the middle) of the small cone-scale; V breadth (at the middle): length ratio of the small cone-scale.

\section{ACKNOWLEDGMENTS}

We thank Mr P. G. Wilson of the Western Australian Herbarium and Dr R. W. Johnson of the Queensland Herbarium, who provided distribution data for the species found in their States. We are especially grateful to Dr B. G. Briggs who has generously allowed us to use her unpublished polygraphs based on the specimens in the National Herbarium of New South Wales. These polygraphs have been prepared for publication by Miss L. Murray.

\section{LITERATURE CITED}

Baker, R. T. \& Smith, H. G. (1910). 'A Research on the Pines of Australia' (Govt Printer: Sydney).

Blake, S. T. (1959). New or noteworthy plants chiefly from Queensland, 1 (Cupressaceae). Proc. Roy. Soc. Queensland 70: 34-39. 
Franco, J. do Amaral (1952). Nomenclatura de algumas coniferas. Anais Inst. Super. Agron. 19: 12-15.

Garden, J. (1957). A revision of the genus Callitris Vent. Contr. New South Wales Natl. Herb. 2: 363-392.

Rudman, P. (1963). Causes of natural durability in timber. Holzforschung 17: 183-188.

Rudman, P. (1964). Causes of natural durability in timber. Holzforschung 18: 52-57.

Stocker, G. F. (1966). Aspects of the seeding habits of Callitris intratropica. Leaflet No. 97. (Australian Forestry and Timber Bureau: Canberra).

Thompson, J. (1961). Contr. New South Wales Natl. Herb. Fl. Ser. Nos 1-18: 46-55.

Manuscript received 11.4.1984. 